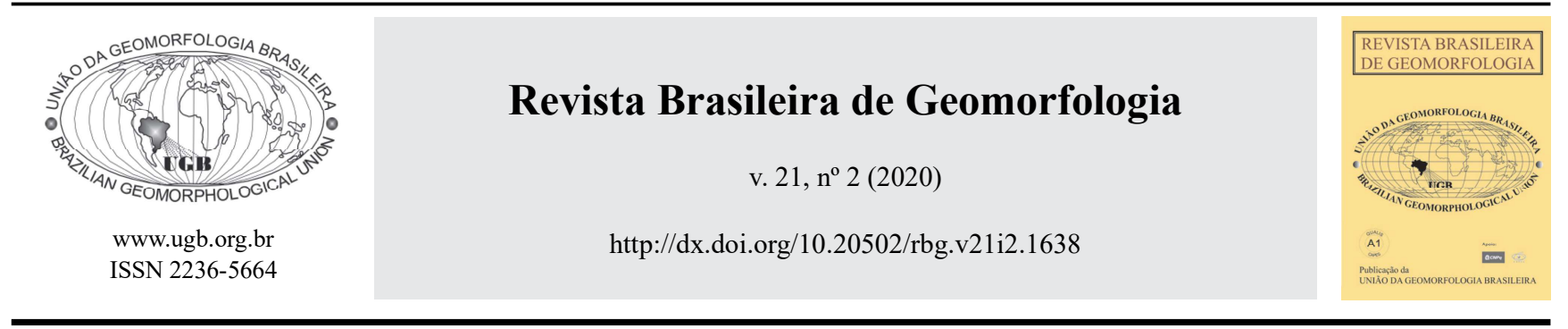

\title{
DINÂMICA GEOMORFOLÓGICA DE SÃO JOSÉ DOS AUSENTES (RS) NO QUARTENÁRIO TARDIO: EVIDÊNCIAS EM PALEOFUNDO DE VALE DE BAIXA ORDEM HIERÁRQUICA
}

\section{GEOMORPHOLOGICAL DYNAMICS OF SÃO JOSÉ DOS AUSENTES (RS) IN THE LATE QUARTENARY: EVIDENCES IN PALEOVALLEY BOTTOM OF LOWER HIERARCHICAL ORDER}

Josielle Samara Pereira

Núcleo de Estudos Paleoambientais, Universidade Estadual do Oeste do Paraná Rua Maringá 1.200, Francisco Beltrão, Paraná. CEP 85.605.010. Brasil ORCID: https://orcid.org/0000-0002-4309-1833 E-mail: josy.samara@hotmail.com

Julio Cesar Paisani

Núcleo de Estudos Paleoambientais, Universidade Estadual do Oeste do Paraná Rua Maringá 1.200, Francisco Beltrão, Paraná. CEP 85.605.010. Brasil ORCID: https://orcid.org/0000-0002-8911-6477 E-mail: juliopaisani@hotmail.com

Sani Daniela Lopes Paisani

Núcleo de Estudos Paleoambientais, Universidade Estadual do Oeste do Paraná Rua Maringá 1.200, Francisco Beltrão, Paraná. CEP 85.605.010. Brasil ORCID: https://orcid.org/0000-0002-9040-0256

E-mail: sanidaniela@hotmail.com

\begin{tabular}{l} 
Informações sobre o Artigo \\
\hline Recebido (Received): \\
22/04/2019 \\
Aceito (Accepted): \\
26/12/2019 \\
\hline
\end{tabular}

\section{Palavras-chave:}

Encosta; Estratigrafia; Colúvio; Paleossolo hidromórfico.

\section{Keywords:}

Hillslope; Stratigraphy; Colluvium; Hydromorphic Paleosoil.

\section{Resumo:}

O presente artigo traz resultados referentes à dinâmica geomorfológica de São José dos Ausentes (RS) no Quaternário tardio, através de registros estratigráficos em paleofundo de vale de baixa ordem hierárquica colmatado. Para o referido estudo, adotou-se, conjuntamente, os critérios lito-, pedo-, alo- e cronoestratigráficos na seção estratigráfica representativa de seus materiais, bem como análises de isótopo estáveis do carbono e fitolítica. Estabeleceu-se a geocronologia pelos métodos de luminescência oticamente estimulada $\mathrm{e}^{14} \mathrm{C}$. A arquitetura da seção estratigráfica revelou três sequências coluviais, respectivamente do topo para a base: coluvial superior pedogenizada, sequência coluvial intermediária e sequência coluvial basal; e uma sequência pedogenética hidromórfica, que se refere ao paleossolo hidromórfico localizado na base da seção. Ao todo foram individualizados 27 níveis pedoestratigráficos além da alterita de riolito. Constatou-se que durante o Último Interestadial (>25.000 anos AP) a paisagem esteve em equilíbrio dinâmico, com dominante atuação da pedogênese, sob condições paleoambientais similares à moderna. Posterior a esse período houve a atuação da morfogênese atuando 
de maneira contínua, gerada pela intercalação entre, discretos movimentos de massa e escoamento superficial. Os discretos movimentos de massa foram responsáveis pelo início da colmatação do fundo de vale. A partir de 19.150 anos AP a sedimentação perdeu intensidade e passou a predominar a erosão, como se observa através de incisão erosiva linear (paleovoçoroca) que truncou o material coluvial basal da seção estratigráfica. Após essa fase de erosão mecânica, a morfogênese retorna a registrar sedimentação comandada pelo escoamento superficial. A partir de 4.860 anos AP a morfogênese continuou atuando, dando origem à sequência coluvial superior, porém perdeu vigor favorecendo a melanização dos materiais propiciando a formação de epipedon, bem como deixou na paisagem uma morfologia similar à encosta suavemente inclinada para o eixo de baixa ordem hierárquica moderna. Diante do quadro evolutivo do paleofundo de vale entende-se que os fenômenos de pedogênese e morfogênese registrados expressam a dinâmica pela qual passou a paisagem geomorfológica de São José dos Ausentes (RS).

\begin{abstract}
:
The present article presents results referring to the geomorphological dynamics of São José dos Ausentes (RS) in the late Quaternary, through stratigraphic records in a paleo valley floor of low hierarchical order cumulate. The criteria of litho-, pedo-, allo- and chronostratigraphic were adopted jointly in the stratigraphic section representative of their materials, as well as analyzes of stable carbon isotopes and phytolytic. Geochronology was established by optically stimulated luminescence and $14 \mathrm{C}$ methods. The architecture of the stratigraphic section revealed three colluvial sequences, respectively from top to bottom: pedogenized upper colluvial sequence, intermediate colluvial sequence and basal colluvial sequence; and a hydromorphic pedogenetic sequence, which refers to the hydromorphic paleosol located at the base of the section. In all, twenty-seven pedestrostratigraphic levels were individualized in addition to the rhyolite alterite. It was found that during the Last Interstate $(>25,000$ years AP) the landscape was in dynamic balance, with a dominant role in pedogenesis, under paleoenvironmental conditions similar to the modern one. After this period, there was the performance of morphogenesis acting in a continuous manner, generated by the intercalation between mass movement and surface flow. The mass movement was responsible for the sedimentation of the valley floor. From 19,150 years AP, sedimentation lost intensity and erosion predominated, as observed through a linear erosive incision (paleovoçoroca) that truncated the colluvial material of the stratigraphic section. After this phase of mechanical erosion, morphogenesis returns to record sedimentation driven by runoff. From 4,860 years AP, the morphogenesis continued to act, giving rise to the superior colluvial sequence, but lost strength favoring the melanization of the materials providing the formation of epipedon, as well as leaving in the landscape a morphology similar to the slope gently inclined to the modern low order axis hierarchical. In view of the evolutionary picture of the paleo valley floor, it is understood that the phenomena of pedogenesis and morphogenesis recorded express the dynamics through which the geomorphological landscape of São José dos Ausentes (RS) went through.
\end{abstract}

\section{Introdução}

São José dos Ausentes localiza-se no nordeste do estado do Rio Grande do Sul (RS) e corresponde ao setor sudeste da Superfície de Cimeira de Vacaria (BIFFI e PAISANI, 2018). Esse setor tem o nível topográfico mais elevado (1.100 a $1.200 \mathrm{~m}$. de altitude) do Planalto Vulcânico da Bacia do Paraná, bem como às Superfícies de Cimeira de Pinhão/Guarapuava e Palmas/Caçador (Figura 1). Essas superfícies de cimeira se encontram na borda leste desse planalto, justamente no reverso da escarpa da Serra Geral, sendo que a última está exclusivamente no Estado do Rio Grande do Sul (BIFFI e PAISANI, 2018).
A paisagem de São José dos Ausentes se assemelha à paisagem de Palmas/Caçador, sendo caracterizada por topografia suavemente ondulada, mantida por derrames de natureza ácida (Riolito) e coberta por vegetação predominantemente de Campos, com Floresta Ombrófila mista ao longo dos fundos de Vales (Figura 1B).

A Superfície Cimeira de Palmas/Caçador vem sendo estudada há uma década e nela foram descobertos depósitos de colúvio, colúvio-alúvio e alúvio, bem como paleossolos enterrados em paleofundos de vales de baixa ordem e rampas de colúvio, que registram fases de estabilidade e instabilidade ambiental ao longo do Quaternário Tardio, que expressam em suas formações 
superficiais a atuação da denudação tanto por fenômenos pedogenéticos quanto morfogenéticos (PAISANI et al., 2013; 2014; 2016; 2017).

Embora com paisagens semelhantes, São José dos Ausentes carece de estudos específicos a respeito da dinâmica de sua paisagem, sobretudo no que se refere à geomorfologia do Quaternário, possivelmente em face da pequena ocorrência de registros estratigráficos (PEREIRA et al., 2016). É buscando suprir essa demanda que o presente artigo foi estruturado, assim, traz resultados de registros estratigráficos em paleofundo de vale colmatado, que figura como exemplo da dinâmica geomorfológica da paisagem de São José dos Ausentes (RS) no Quaternário Tardio.

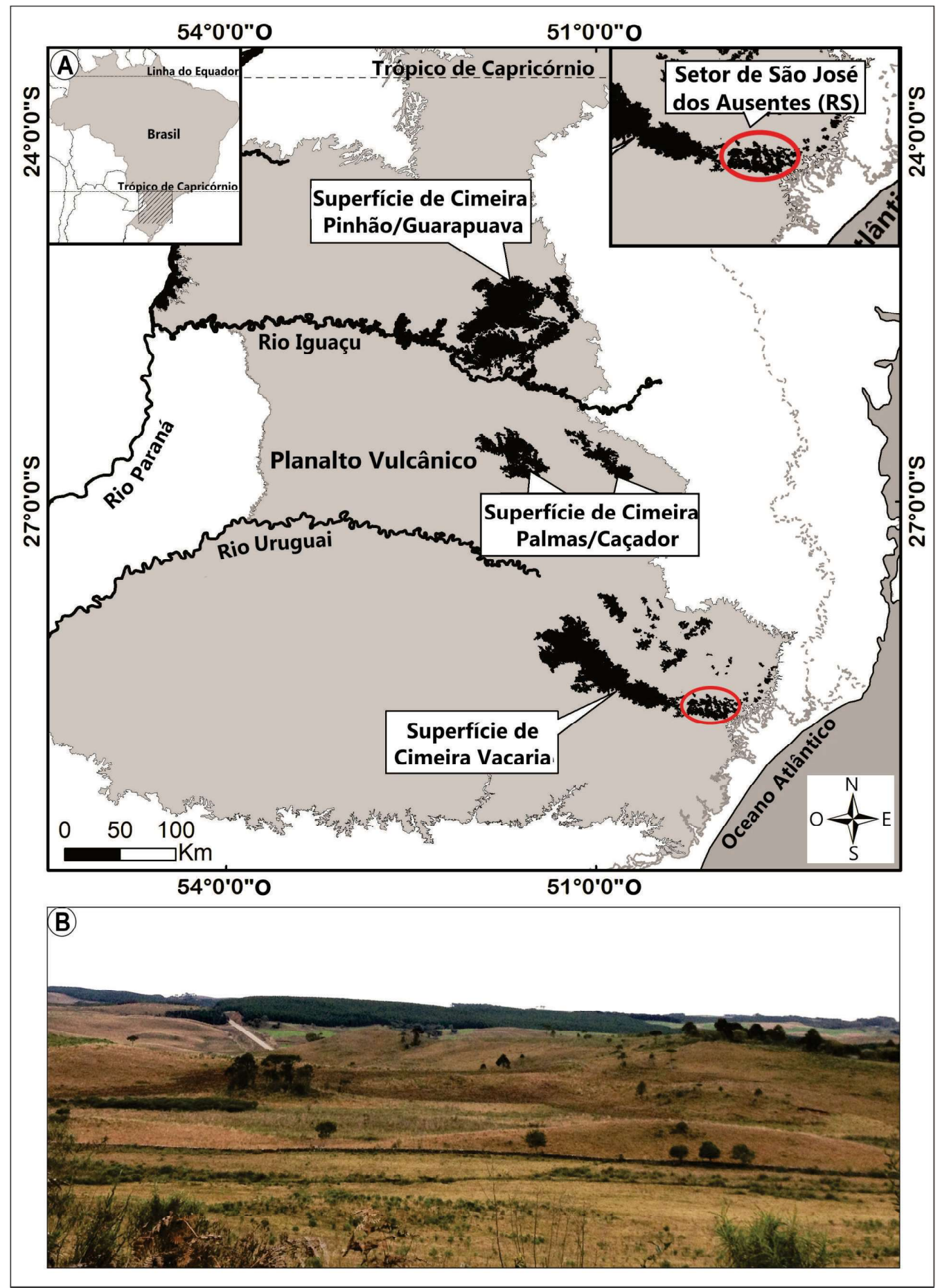

Figura 1 - (A) Superfície de Cimeira de Vacaria no setor de São José dos Ausentes (RS) no contexto regional do Planalto Vulcânico da Bacia do Paraná (adaptação: Paisani et al., 2019). (B) Paisagem do setor de São José dos Ausentes. 


\section{2. Área de estudo}

As formações superficiais de São José dos Ausentes são rasas e restritas a fundo de vales modernos e paleocanais colmatados, os quais são detectados pela geometria dos registros estratigráficos por ocasião de coincidirem com cortes de estrada. Esse é o caso do paleofundo de vale colmatado de baixa ordem hierárquica que foi identificado e designado de seção SJA1, localizada em corte de estrada na rodovia (BR-285) que liga os municípios de Bom Jesus (RS) e São José dos Ausentes (RS) (Figura 2).

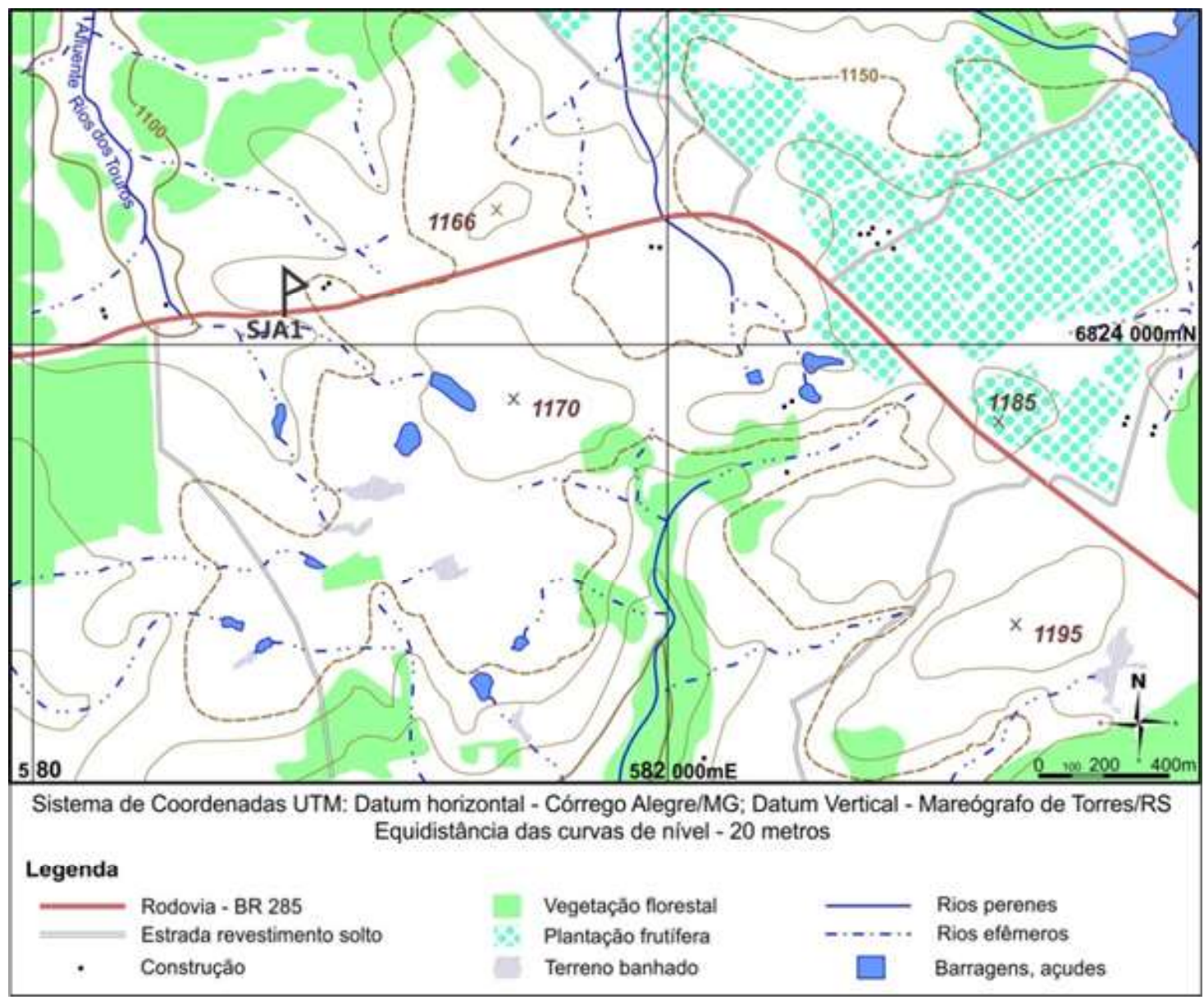

Figura 2 - Localização da seção estratigráfica SJA1.

O paleofundo de vale colmatado se estabeleceu sobre derrames vulcânicos de natureza ácida (riolito), com fácies hidrotermalizada, do Grupo São Bento (WILDNER et al., 2006), Supergrupo Gondwana III (MILANI, 2004). O relevo se apresenta suave-ondulado a ondulado, contendo platôs com abruptas encostas, terminadas em várzeas não muito extensas e planícies recortadas por vales fluviais (SCHLICK, 2004).

O paleofundo de vale está situado justamente no alto curso da Bacia Hidrográfica do Rio dos Touros. Sua bacia possui um perímetro correspondente a $146,52 \mathrm{~km}$ e uma área de aproximadamente $543 \mathrm{~km}^{2}$ (CAVAZINI et al., 1016). O Rio dos Touros é um afluente do Rio Pelotas, que está situado na divisa entre os estados de Santa
Catarina e Rio Grande do Sul (PELUSO JUNIOR, 1986).

Os solos são classificados como Cambissolos Húmicos Distrófico e Neossolos Litólicos Eutrófico e Órtico (IBGE - EMBRAPA, 2001). Em relação à cobertura vegetal, a área é caracterizada por paisagem de campo com manchas de florestas de araucária e turfeiras (IBGE, 2004, MMA, 2009; SCHERER e LORSCHEITTER, 2014).

O Clima regional é classificado como $\mathrm{Cfb}(\mathrm{C}$ : clima mesotérmico temperado; f: Clima úmido, com chuva bem distribuída durante o ano todo; b: verão temperado) (KUINCHTNER e BURIOL, 2001). A série histórica de pluviosidade e tempertarura média para a área de estudo se apresenta com temperatura inferior aos $20^{\circ} \mathrm{C}$ e com temperaturas médias próximas aos $10^{\circ} \mathrm{C}$ 
para os meses de junho e julho. No que se refere às médias mensais pluviométricas, elas se apresentam bem distribuidas ao longo do ano, com $160 \mathrm{~mm}$ nos meses mais chuvosos (janeiro, fevereiro, agosto e setembro) e precipitações que variam entre $103 \mathrm{~mm}$ e $112 \mathrm{~mm}$ nos meses mais secos.

\section{Materiais e Métodos}

A seção estratigráfica transversal ao eixo de paleofundo de vale de segunda ordem hierárquica colmatado, seção SJA1, apresenta aproximadamente $30,70 \mathrm{~m}$ de comprimento e $6 \mathrm{~m}$ de altura (Figura 3 ). Nela foi possível individualizar, sedimentos coluviais e paleossolo hidromórfico.

Diante das características genéticas do registro estratigráfico, adotou-se como abordagem metodológica o uso conjugado dos critérios lito-, pedo-, alo- e cronoestratigráficos (HUGUES, 2010), similarmente ao que vem sendo feito para registros estratigráficos em paleofundos de vales de baixa ordem hierárquica e rampas de colúvio na Superfície de Palmas/Água Doce (PAISANI et al., 2012; 2014; 2016; 2017).

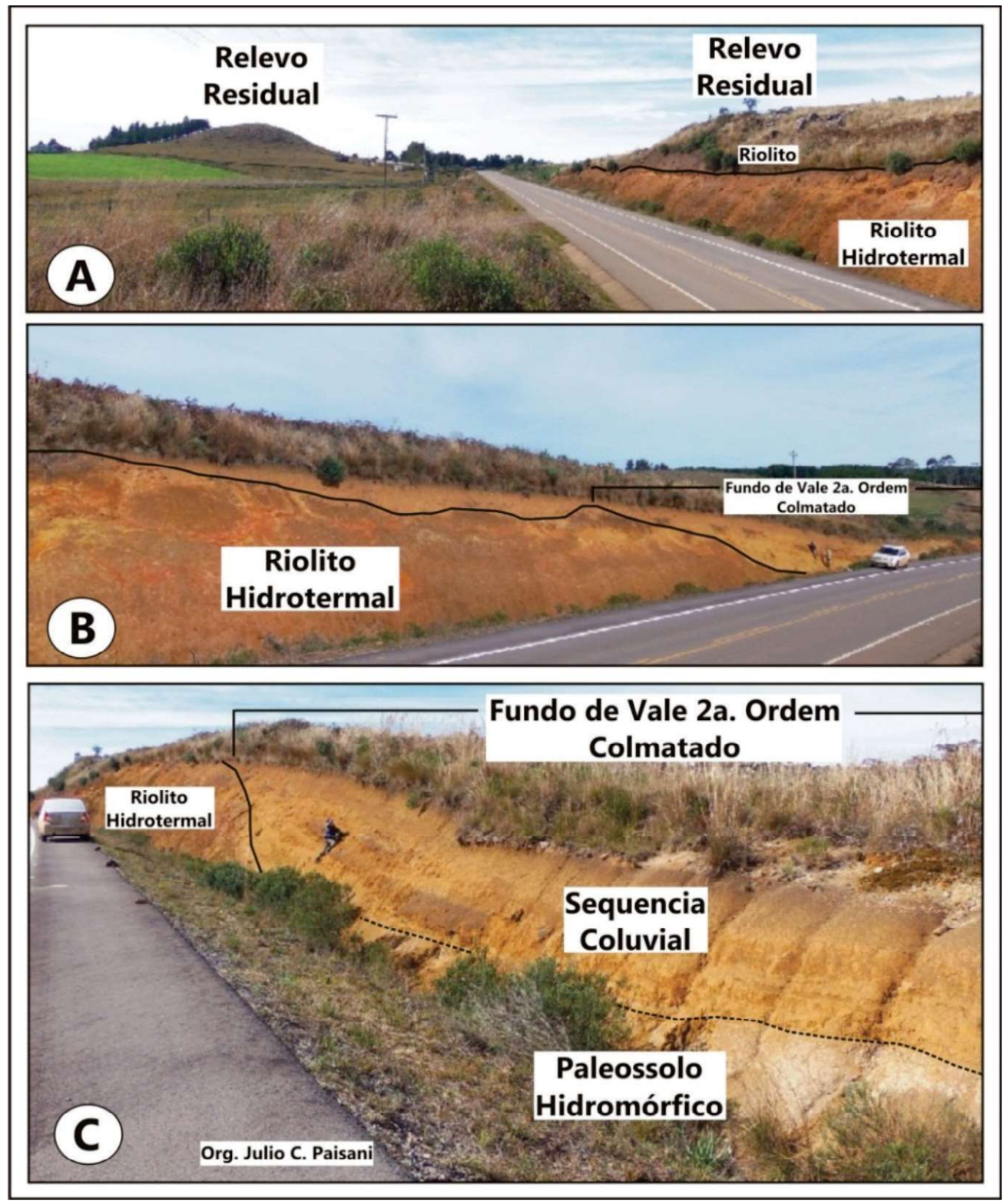

Figura 3 - Contexto Geomorfológico de paleofundo de vale de segunda ordem colmatado na superfície de São José dos Ausentes (seção SJA1). (A) Relevos residuais contendo caos de blocos de riolito. (B) Disposição lateral do relevo até o fundo de vale colmatado. (C) Seção estratigráfica transversal ao fundo de vale colmatado. Destacam-se sequência coluvial indiferenciada e paleossolo hidromórfico no eixo do fundo de vale. 
A caracterização e a descrição da seção iniciaram-se com a sua limpeza; após seguiu-se com o reconhecimento de unidades e descontinuidades estratigráficas, utilizando-se critérios litológicos, bem como da aplicação da descrição morfológica pedológica e da nomenclatura pedoestratigráfica (PAISANI et al., 2016). Em relação às unidades litológicas, foram descritas com base nos seguintes critérios: a) individualização e nomenclatura das unidades estratigráficas; b) geometria externa; c) contato entre unidades; d) gradação; e) tipo de estratificação; f) presença e propriedade dos clastos; g) bioturbação; h) cor, através da Carta de Munsell. Já, para os critérios pedológicos foram considerados: a) cor, através da Carta de Munsell; b) estrutura; c) consistência; d) resistência; e) porosidade; f) bioturbação; g) transição inferior e h) presença de feições pedológicas.

Procedeu-se o reconhecimento e a descrição das propriedades macroscópicas dos materiais e a reprodução da arquitetura estratigráfica da seção (geometria externa) em papel milimetrado na escala 1:20. Um total de 79 amostras deformadas foram coletadas de forma sistemática, a cada $10 \mathrm{~cm}$ de profundidade, visando estabelecer a diagrafia granulométrica (PAISANI, 2005). As classes texturais das unidades estratigráficas foram estabelecidas com base no diagrama triangular - cujas divisões se baseiam em Schaetzel e Anderson (2005). Dos principais níveis estratigráficos, 12 amostras, foram utilizadas, respectivamente, para a determinação da composição isotópica estável do carbono. A composição isotópica estável do carbono tem sido aplicada para os estudos da reconstrução paleoambiental no Sul do Brasil (PESSENDA, 1996 et al.; PESSENDA et al., 2005; CALEGARI, 2008; PAISANI et al., 2013; 2014). Igualmente, aplicou-se essa análise para estimar as formações vegetais que ocuparam o fundo de vale e suas encostas ao longo do tempo.

De modo a auxiliar a análise de isótopos estáveis do carbono foram coletadas, sistematicamente, a cada $10 \mathrm{~cm}$ de profundidade, 59 amostras do registro estratigráfico e todas submetidas à análise fitolítica. A extração, contagem e classificação de fitólitos se baseou, respectivamente, em Alvarez et al. (2008), Calegari et al. (2013) e Madella et al. (2005) e foram realizadas nos laboratório de Extração de Fitólitos e Microscopia Ótica do Núcleo de Estudos
Paleoambientais (NEPA) da Universidade Estadual do Oeste do Paraná (UNIOESTE) campus de Francisco Beltrão.

A granulometria foi realizada por peneiramento para a fração grossa e pipetagem para a fração fina, com separação via úmida utilizando-se CALGON (PAISANI, 1998). A análise granulométrica e a preparação de amostras para a determinação da composição isotópica do carbono foram realizadas no NEPA - UNIOESTE, ao passo que a composição isotópica do carbono e o carbono total foram determinadas pelo Laboratório de Isótopos Estáveis do CENA-USP (Piracicaba, SP).

Para a determinação da geocronologia dos materiais, três amostras foram submetidas para datação por luminescência oticamente estimulada (LOE) com 15 alíquotas (método SAR) em grãos de quartzo, sendo realizada pelo laboratório de Datação Comércio \& Prestação de Serviços LTDA, em São Paulo (SP). A idade definida pela LOE é a data na qual a amostra foi exposta a luz solar pela última vez. Ao serem transportados, os sedimentos sofrem fotoesvaziamento pela luz solar, sobrando apenas o nível de luz residual. Logo quando soterrado, o sedimento fica protegido da luz solar e a energia da radiação ionizante ambiental se acumula nos minerais. Assim, a idade de sedimentação pode ser determinada dividindo a dose acumulada desde o soterramento do sedimento pela dose anual de radiação natural (Guedes et al., 2011).

Por fim, uma amostra foi submetida para a datação pelo método do carbono quatorze $\left({ }^{14} \mathrm{C}\right)$, coletada do paleossolo hidromórfico, rico em raízes fasciculadas. Esta datação é aplicada em materiais onde se encontra matéria orgânica, geralmente que compõem paleossolos (Suguio, 1999 e 2003; Pessenda, 2005. As idades obtidas por esse método foram calibradas pela empresa Beta Analytic Radiocarbon Dating - USA e com a utilização do programa calib radiocarbon calibration ver.7.0.4 (STUIVER et al. 2018), com base no modelo SHCal13: Southern Hemisphere (HOGG et al. 2013).

\section{Resultados e Discussões}

\subsection{Unidades Pedoestratigráficas}

A arquitetura da seção estratigráfica revelou três sequências coluviais, designadas do topo para a 
base de superior pedogenizada, intermediária e basal, além de paleossolo hidromórfico enterrado (Figura 4). Os sedimentos coluviais se encontram dispostos de forma plano-paralela, individualizados pela intercalação de camadas arenosas com lamonosas. Cada nível coluvial corresponde a uma descontinuidade litoestratigráfica, o que implicou na aplicação de números arábicos para sua individualização, conforme o critério pedoestratigráfico (Figura 4). O paleossolo hidromórfico enterrado se desenvolveu em sedimentos aluviais de canal de segunda ordem hierárquica e tem como descontinuidade estratigráfica superior, nível concentrando óxi-hidróxidos de ferro de forma laminar (Figura 4). Já, a sequência coluvial basal é limitada por evento erosivo que gerou, além do truncamento lateral das camadas superiores, incisão erosiva linear (paleovoçoroca) (Figura 4). O limite das sequências coluviais intermediária e superior é marcado pela homogeneização dos sedimentos coluviais nessa última, em decorrência da pedogenização. Por fim, as descrições pedomorfológicas refinaram os registros estratigráficos que, em essência, correspondem a sedimentos (horizonte $\mathrm{C}$ ) com diferentes graus de pedogênese, como mostra a nomenclatura pedoestratigráfica (Figura 4; Tabela 1).

Em síntese, foram individualizados vinte e sete horizontes ao longo da seção estratigráfica, sendo que a sequência coluvial superior pedogeneizada exibe três horizontes (A, AC e CA), a sequência coluvial intermediária contém 13 horizontes $(2 \mathrm{Cb}, 3 \mathrm{Cb}, 4 \mathrm{Cb}$, $5 \mathrm{Cb}, 6 \mathrm{Cb}, 7 \mathrm{Cb}, 8 \mathrm{Cb}, 9 \mathrm{Cb}, 10 \mathrm{Cb}, 11 \mathrm{Cb}, 12 \mathrm{Cb}, 13 \mathrm{Cb}$, $14 \mathrm{Cb}$ ), ao passo que a sequência coluvial basal tem sete horizontes $(15 \mathrm{Cb}, 16 \mathrm{Cb}, 17 \mathrm{Cb}, 18 \mathrm{Cb}, 19 \mathrm{Cb}$, $20 \mathrm{Cb}$ e $21 \mathrm{Cg} 1 \mathrm{~b}$ ), enquanto o paleossolo hidromórfico flúvico preserva seis horizontes $(22 \mathrm{Cg} 2 \mathrm{~b}, 23 \mathrm{Cg} 3 \mathrm{~b}$, $24 \mathrm{Ccg} 4 \mathrm{~b}, 25 \mathrm{Cg} 5 \mathrm{~b}, 26 \mathrm{Cg} 6 \mathrm{~b}$ e $27 \mathrm{RCg} 7)$, além da alterita de riolito que constitui o horizonte $28 \mathrm{RCg} 7$ (Figura 4 e 5A). A análise granulométrica relevou compatibilidade com os níveis pedoestratigráficos identificados por ocasião da descrição morfopedológica em campo (Figura 5B).

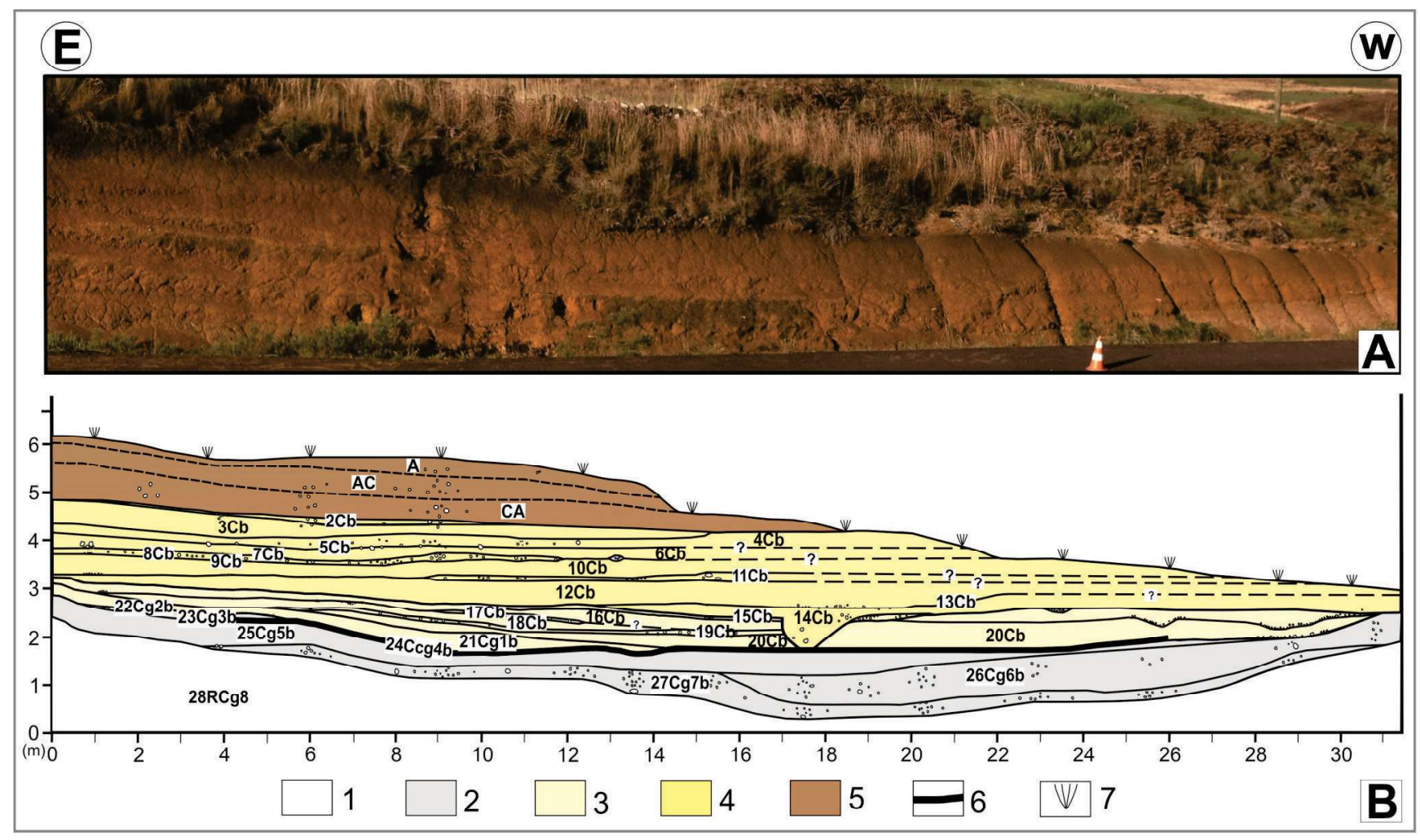

Figura 4 - Seção estratigráfica SJA1. (A) Foto da seção estratigráfica e (B) Arquitetura da seção estratigráfica com a definição dos horizontes: Alterita de Riolito; 2: Sequência pedogenética hidromórfica; 3: Sequência coluvial basal; 4: Sequencia coluvial intermediária; 5: Sequência coluvial superior pedogeneizada; 6: Crosta de Ferro; 7: gramineas. 
Pereira J. S. et al.

Tabela 1: Atributos morfopedológicos dos horizontes da Seção SJA1.

\begin{tabular}{|c|c|c|c|c|c|c|c|c|}
\hline \multirow{2}{*}{ Horiz. } & \multirow{2}{*}{$\begin{array}{l}\text { Espessura } \\
\text { média (cm) }\end{array}$} & \multicolumn{2}{|c|}{ Cor $^{1}$} & \multirow{2}{*}{ Textura $^{2}$} & \multicolumn{2}{|c|}{ Consistência ${ }^{3}$} & \multirow{2}{*}{ Estrutura $^{4}$} & \multirow{2}{*}{ Outras características } \\
\hline & & Seco & Úmido & & Seco & Molhado & & \\
\hline A & 27 & 10.YR $2 / 2$ & 10.YR 2/1 & $\mathrm{Ar}$ & $\mathrm{Ldu}$ & Lpe e Lpl & Bs - Moderado & $\begin{array}{l}\text { Horizonte superficial, } \\
\text { apresenta grumos, } \\
\text { litorrelíqueas e raízes }\end{array}$ \\
\hline $\mathrm{AC}$ & 40 & 10.YR 3/2 & 10.YR 3/2 & $\mathrm{Ar}$ & $\mathrm{Ldu}$ & Lpe e Lpl & Bs - Moderado & $\begin{array}{c}\text { Fragmentos de } \\
\text { litorrelíquea aleatórios }\end{array}$ \\
\hline $\mathrm{CA}$ & 50 & 10. YR 4/4 & 10. YR 4/4 & $\mathrm{Ar}$ & $\mathrm{Ldu}$ & Lpe e Lpl & $\begin{array}{l}\text { Bs - Moderado } \\
\text { a forte }\end{array}$ & $\begin{array}{c}\text { Fragmentos de } \\
\text { litorrelíquea aleatórios }\end{array}$ \\
\hline $2 \mathrm{Cb}$ & 9 & - & - & - & - & - & - & Linha de pedra \\
\hline $3 \mathrm{Cb}$ & 32 & 10. YR 5/6 & 10. YR 4/4 & $\mathrm{Ar}$ & $\mathrm{Ldu}$ & Lpe e Lpl & $\begin{array}{l}\text { Bs - Moderado } \\
\text { a forte }\end{array}$ & $\begin{array}{c}\text { Estrutura com tendência } \\
\text { a prismática }\end{array}$ \\
\hline $4 \mathrm{Cb}$ & 25 & 10. YR 5/8 & 10. YR 4/6 & $\mathrm{Ar}$ & $\mathrm{Ldu}$ & Lpe e Lpl & Gr a Bs - fraco & Com pedras esparsas \\
\hline $5 \mathrm{Cb}$ & 3 & 10. YR 4/6 & 10. YR 4/4 & $\mathrm{Ar}$ & $\mathrm{Ldu}$ & Lpe e Lpl & Gr a Bs-fraco & Linha de pedra \\
\hline $6 \mathrm{Cb}$ & 25 & 10. YR 4/6 & 10. YR 4/4 & $\mathrm{Ar}$ & $\mathrm{Ldu}$ & Lpe e Lpl & Gr a Bs-fraco & $\begin{array}{l}\text { Nível homogêneo com } \\
\text { pedras esparsas }\end{array}$ \\
\hline $7 \mathrm{Cb}$ & 3 & 10. YR 4/6 & 10. YR 4/6 & Fr Si Ar & $\mathrm{Ldu}$ & Lpe e Lpl & $\begin{array}{c}\text { Bs - Moderado } \\
\text { a fraco }\end{array}$ & Linha de pedra \\
\hline $8 \mathrm{Cb}$ & 20 & 10. YR 4/6 & 10. YR 4/6 & $\mathrm{Ar}$ & $\mathrm{Ldu}$ & Lpe e Lpl & $\begin{array}{c}\text { Bs - Moderado } \\
\text { a fraco }\end{array}$ & Com pedras esparsas \\
\hline $9 \mathrm{Cb}$ & 3 & 10. YR 4/6 & 10. YR 4/6 & Fr Ar & $\mathrm{Ldu}$ & Lpe e Lpl & $\begin{array}{c}\text { Bs - Moderado } \\
\text { a fraco }\end{array}$ & Linha de pedra \\
\hline $10 \mathrm{Cb}$ & 33 & 10. YR 4/6 & 10. YR 4/6 & Fr Ar & $\mathrm{Ldu}$ & Lpe e Lpl & $\begin{array}{l}\text { Bs - Moderado } \\
\text { a fraco }\end{array}$ & Nível homogêneo \\
\hline $11 \mathrm{Cb}$ & 14 & 10. YR 5/6 & 10. YR 4/6 & $\mathrm{Ar}$ & $\mathrm{Ldu}$ & Lpe e Lpl & Bs - Moderado & Linha de pedra \\
\hline $12 \mathrm{Cb}$ & 37 & 10. YR 5/6 & 10. YR 5/6 & $\mathrm{Ar}$ & Ldu & Lpe e Lpl & Bs - Moderado & Homogêneo. \\
\hline $13 \mathrm{Cb}$ & 3 & 10. YR 5/6 & 10. YR 5/6 & Fr Si Ar & $\mathrm{Ldu}$ & Lpe e Lpl & $\begin{array}{c}\text { Bs - Moderado } \\
\text { a fraco }\end{array}$ & Linha de pedra \\
\hline $14 \mathrm{Cb}$ & 42 & 10. YR 5/6 & 10. YR 4/6 & $\mathrm{Ar}$ & $\mathrm{Ldu}$ & Lpe e Lpl & Bs - Moderado & Voçoroca \\
\hline $15 \mathrm{Cb}$ & 7 & 10. YR 5/6 & 10. YR 5/6 & Fr Si Ar & $\mathrm{Ldu}$ & Lpe e Lpl & $\begin{array}{l}\text { Bs - Moderado } \\
\text { a fraco }\end{array}$ & Linha de pedra \\
\hline $16 \mathrm{Cb}$ & 20 & 10. YR 5/6 & 10. YR 4/6 & $\mathrm{Ar}$ & $\mathrm{Ldu}$ & Lpe e Lpl & $\begin{array}{l}\text { Bs - Moderado } \\
\text { a fraco }\end{array}$ & Homogêneo \\
\hline $17 \mathrm{Cb}$ & 6 & 10. YR 5/8 & 10. YR 5/8 & $\mathrm{Ar}$ & $\mathrm{Ldu}$ & Lpe e Lpl & $\begin{array}{l}\text { Bs - Moderado } \\
\text { a fraco }\end{array}$ & Linha de pedra \\
\hline $18 \mathrm{Cb}$ & 17 & 10. YR 5/8 & 10. YR 4/6 & $\mathrm{Ar}$ & $\mathrm{Ldu}$ & Lpe e Lpl & $\mathrm{Ma}$ & Homogêneo \\
\hline $19 \mathrm{Cb}$ & 8 & 10. YR 5/8 & 10. YR 4/6 & $\mathrm{Ar}$ & $\mathrm{Du}$ & Lpe e Lpl & $\mathrm{Ma}$ & Linha de pedra \\
\hline $20 \mathrm{Cb}$ & 40 & 10. YR 5/6 & 10. YR 4/6 & $\mathrm{Ar}$ & $\mathrm{Ldu}$ & Lpe e Lpl & Bs-Moderado & Homogêneo \\
\hline $21 \mathrm{Cg} 1 \mathrm{~b}$ & $25 \mathrm{t}$ & 10. YR 5/8 & 10. YR 4/6 & $\mathrm{Ar}$ & $\mathrm{Ldu}$ & Lpe e Lpl & Bs-fraca & $\begin{array}{l}\text { Presença de raízes } \\
\text { fasciculadas }\end{array}$ \\
\hline $21 \mathrm{Cg} 1 \mathrm{~b}$ & $25 b$ & 10. YR 5/4 & 10. YR 5/6 & $\mathrm{Ar}$ & $\mathrm{Ldu}$ & Lpe e Lpl & Bs-fraca & $\begin{array}{l}\text { Lente laranja, presença } \\
\text { de raízes pivotantes - } \\
\text { Crosta de ferro (limite } \\
\text { inferior) }\end{array}$ \\
\hline $22 \mathrm{Cg} 2 \mathrm{~b}$ & 3 & - & - & - & - & - & - & Linha de pedra \\
\hline
\end{tabular}




\begin{tabular}{c|c|c|c|c|c|c|c|c}
\hline $23 \mathrm{Cg} 3 \mathrm{~b}$ & 10 & $10 . \mathrm{YR} 5 / 4$ & $10 . \mathrm{YR} 5 / 6$ & Fr Ar & Ldu & Lpe e Lpl & Bs-fraca & - \\
\hline $24 \mathrm{Ccg} 4 \mathrm{~b}$ & 6 & - & - & - & - & - & - & Crosta de Ferro \\
\hline $\begin{array}{c}25 \mathrm{Cg} 5 \mathrm{~b} \\
\text { (topo) }\end{array}$ & 35 & $10 . \mathrm{YR} 5 / 4$ & $10 . \mathrm{YR} 5 / 6$ & $\mathrm{Ar}$ & Ldu & Lpe e Lpl & Bs-fraca a Ma & $\begin{array}{c}\text { Crosta de ferro (limite } \\
\text { superior) }\end{array}$ \\
\hline $\begin{array}{c}25 \mathrm{Cg} 5 \mathrm{~b} \\
\text { (base) }\end{array}$ & 35 & $2.5 \mathrm{Y} \mathrm{7/3}$ & 2.5 Y 6/4 & Ar & Ldu & Npe e Npl & Ma & $\begin{array}{c}\text { Conglomerado com } \\
\text { matriz suportada, traço } \\
\text { de raízes circulares e } \\
\text { fasciculadas milimétricas, } \\
\text { com pedras esparsas. }\end{array}$ \\
\hline $26 \mathrm{Cg} 6 \mathrm{~b}$ & 53 & $2.5 \mathrm{Y} \mathrm{7/3}$ & $2.5 \mathrm{Y} \mathrm{6/4}$ & Fr & Ldu & Lpe e Lpl & Ma & $\begin{array}{c}\text { Presença de raízes e } \\
\text { seixo, grânulo, quartzo. }\end{array}$ \\
\hline $27 \mathrm{Cg} 7 \mathrm{~b}$ & 27 & $2.5 \mathrm{Y} \mathrm{7/3}$ & $2.5 \mathrm{Y} \mathrm{6/4}$ & Fr Are & Ldu & Npe e Npl & Ma & $\begin{array}{c}\text { Conglomerado com } \\
\text { matriz suportada, traço } \\
\text { de raízes fasciculadas } \\
\text { milimétricas, com com } \\
\text { pedras esparsas }\end{array}$ \\
\hline
\end{tabular}

${ }^{1}$ Carta de Munsell; ${ }^{2}$ Conforme diagrama triangular da USDA (Schaetzl \& Anderson, 2005), Ar: Argiloso, Fr: Franco, Si: Siltoso; Are: Arenoso ${ }^{3}$ Ldu: Ligeiramente dura; Du: Dura; So: Solta; Fr: Friável; Mf: Muito friável; Fi: Firme; Npe: Não pegajosa; Npl: Não plástica; Lpe: Ligeiramente pegajoso; Lpl: Ligeiramente plástico; ${ }^{4}$ Bs: blocos subangulares; Ma: maciça; Gr: granular; (-) não foi determinado a caracterização fisica do material

A análise micromorfológica realizada por Pereira (2017) revelou que a sequência coluvial basal apresenta microlaminações vinculadas à disposição da fração grossa, sugerindo a sedimentação do material devido ao escoamento superficial (ARAÚJO et al., 2017). No geral, através da micromofologia os materiais das matrizes dos horizontes mostram-se similares, sugerindo se tratar de materiais oriundos na mesma fonte e fase pedogenética. A sedimentação coluvial misturou níveis pedológicos da área fonte com diferentes graus de pedogênese/intemperismo, dada a presença de fragmentos líticos e nodulações, dentre outras microfeições. As microfeições indicaram recorrência de ciclos de saturação e dissecação na área fonte, constituindo um componente paleoambiental, pois indicam regime climático com estações bem definidas. A depleção (perda de material) e fraca pedalidade é um fenômeno de maior importância na sequência coluvial superior sugerindo retomada da pedogênese em condições ambientais (climáticas e edáficas) modernas (PEREIRA, 2017).

\subsection{Isótopos estáveis do Carbono ( $\delta$ 13C)}

A análise isotópica do carbono foi realizada nos horizontes $\mathrm{A}, \mathrm{AC}, \mathrm{CA}, 3 \mathrm{Cb}, 6 \mathrm{Cb}, 10 \mathrm{Cb}, 14 \mathrm{Cb}, 16 \mathrm{Cb}$, $18 \mathrm{Cb}, 21 \mathrm{Cg} 1 \mathrm{~b}, 25 \mathrm{Cg} 5 \mathrm{~b}, 26 \mathrm{Cg} 6 \mathrm{~b}$ (Figura 5C). Os valores do carbono total dos horizontes pedoestratigráficos variaram de 3,45 (Horizonte A) a 0.23 (Horizonte $27 \mathrm{Cg} 7 \mathrm{~b}$ ) enquanto para o $\delta 13 \mathrm{C}$ variaram de $-12,90 \mathrm{a}$
$-23,72$ partes por mil. Nos horizontes mais superfícies os valores se mostraram menos negativos, A $(-12,90)$, AC $(-14,92)$ e CA $(-18,02)$. A partir do horizonte $3 \mathrm{Cb}$ em direção à base da seção, os valores apresentaram-se mais negativos, mas mantendo acima de $-20,77$ conforme pode ser observado no horizonte $3 \mathrm{Cb}$, chegando a $-23,62$ no horizonte $26 \mathrm{Cg} 6 \mathrm{~b}$, sendo esse o valor mais negativo.

Os valores da razão isotópica dos níveis estratigráficos mais superfícies, sendo eles A e AC, apontam para o predomínio de uma vegetação C4 (gramíneas), pois se observa um valor isotópico mais negativo que -17 (Pessenda et al., 1996; 2005). Já, o horizonte CA mostra mistura de vegetação C4 com C3 (arbustos e arbórea), visto que seu valor se apresenta mais elevado que -17. Observa-se, a partir do horizonte $3 \mathrm{Cb}$ até o $14 \mathrm{Cb}$, valores isotópicos que caracterizam uma vegetação predominante $\mathrm{C} 3$, pois apresenta razão isotópica entre -22 a -20 . Entre os horizontes $15 \mathrm{Cb}$ e $21 \mathrm{Cgb}$ predomina vegetação de plantas $\mathrm{C} 3$, uma vez que os valores isotópicos estão mais negativos que -22. Assim, pode-se dizer que o paleossolo e a sequência coluvial inferior apresentam composição isotópica de plantas $\mathrm{C} 3$, enquanto a sequência intermediária de mistura de $\mathrm{C} 3$ e $\mathrm{C} 4$, com nítida mudança de tendência isotópica entre os horizontes $16 \mathrm{Cb}$ e $14 \mathrm{Cb}$. Ao passo que a sequência coluvial superior, melanizada, mostra-se com predomínio de plantas $\mathrm{C} 4$, similarmente à constituição moderna, caracterizada por campos com composição herbácea-arbustiva. 


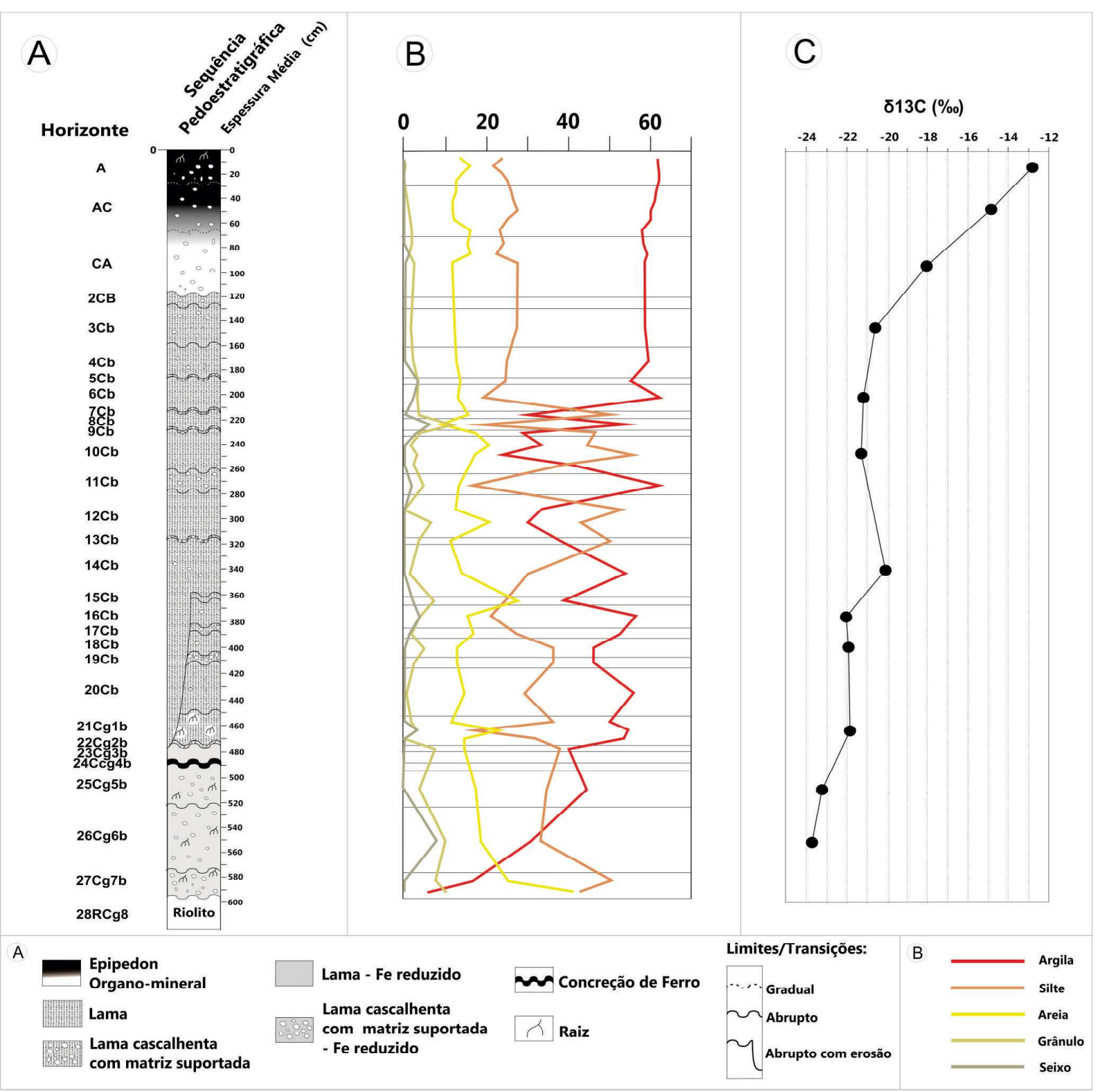

Figura 5 - A: Distribuição e classificação dos horizontes estratigráficos da seção SJA1 disposta em seção colunar. B: Diagrafia Granulométrica. C: Conteúdo de $\delta^{13} \mathrm{C}$ (isótopos estáveis do carbono).

\subsection{Análise Fitolítica}

A concentração de fitólitos no registro pedoestratigráfico no epipedom moderno (horizontes A e AC), ficou em 45,85 a $11,86 \%$, no endopedom (horizontes $2 \mathrm{Cb}$ a $26 \mathrm{Cgb}$ ), é de 0 a $2,58 \%$. A distribuição vertical dos fitólitos mostra tendência de redução da concentração conforme a profundidade, logo na passagem entre os horizontes $\mathrm{A}$ e AC, ficando próxima de zero no horizonte CA. Isso leva a pensar que os fitólitos desses horizontes estão vinculados ao sinal da vegetação moderna e à melanização dos níveis pedoestratigráficos superiores, cujo processo de transferência pedogenética (eluviação) forne- ceu poucas biomineralizações para os níveis inferiores do registro estratigráfico. Nesse caso, sugere que os níveis pedoestratigráficos inferiores guardam remanescentes de fitólitos vinculados à gênese alóctone dos materiais.

A baixa concentração de fitólitos nos níveis pedoestratigráficos inferiores deve estar vinculada a processos tafonômicos de degradação dos fitólitos (OSTERRIETH et al., 2009). A análise fitolítica deles mostrou que predominam fitólitos alterados tanto quimicamente (decomposto e carbonizados) quanto fisicamente (quebrados), com predomínio de carbonizados. A alteração física e química da morfologia dos fitólitos 
decorre de processos deposicionais e pós-deposicionais (OSTERRIETH et al., 2009). Os alterados fisicamente podem expressar o desgaste por processos mecânicos de transporte, em que a tensão mecânica sofrida durante o transporte provoca seu rompimento (quebra), similarmente ao que ocorre com sedimentos clásticos. No caso do registro estratigráfico estudado, os níveis pedoestratigráficos derivam de sedimentos coluviais gerados por fluxos discretos de escoamento superficial em curtas distâncias quando a intensidade da chuva supera a capacidade de infiltração do solo (fluxo hortoniano). Esse mecanismo de sedimentação teria maior eficiência em promover alterações físicas e fragmentação dos fitólitos por atrito com as paleosuperfícies, caso a distância de percurso fosse elevada e o fluxo fosse contínuo. No entanto, a curta distância associada ao fluxo efêmero, comum ao escoamento superficial hortoniano (SELBY, 1994), reduz a possibilidade de atrito entre as partículas e a paleosuperfície, de modo que não pode ser responsável pelos fitólitos alterados fisicamente.

No caso da alteração química de processos biogeoquímicos associados à pedogênese ou diagênese, podem atacar os fitólitos ao longo do tempo mediante condições de possível ambiente com $\mathrm{pH}$ alcalino na área fonte dos sedimentos, ou no local de sedimentação, promovendo a decomposição dos fitólitos encontrados em registros pedoestratigráficos (ALEXANDRE et al., 1997; 1999; OSTERRIETH et al., 2009; COSTA et al., 2010). Fitólitos com maior superfície específica e impurezas são os mais susceptíveis à alteração química (OSTERRIETH et al., 2009). Como a categoria de fitólitos alterados quimicamente ocorre em todos os níveis pedoestratigráficos inferiores, pode-se pensar que fitólitos alterados decorrem tanto da pedogênese dos materiais na área fonte quanto de processos de decomposição pós-deposicionais.

Fitólitos carbonizados são aqueles alterados pela queima. Eles denunciam que as plantas passaram por uma ou mais fases de submissão ao fogo. Sua presença em todos os níveis pedoestratigráficos aponta para paleoincêndios recorrentes, que podem ser naturais ou induzidas por paleoíndios (PILLAR et al., 2009).

Nos níveis pedoestratigráficos inferiores também foram encontrados fitólitos alterados tanto quimicamente quanto fisicamente, predominando fitólitos alterados quimicamente $(50,47$ a $51,43 \%)$. Um mecanismo responsável pela alteração tanto física quanto química de fitólitos foi investigado por Paisani (2015) em condições ambientais modernas. Analisando fitólitos de bolos fecais de gado em área de pastagem na Superfície de Palmas/ Caçador, e sua transferência para os níveis superficiais do solo, a autora constatou que o processo de mastigação e decomposição digestiva desses animais herbívoros produziu fitólitos com alteração tanto física quanto química e de elevada concentração relativa nos níveis superficiais do solo. Tomando esse achado como referência para presença de fitólitos no epipedom da área de estudo, pode-se pensar que fitólitos alterados presentes nesse nível pedoestratigráfico expressam a mastigação durante a pastagem do gado e subsequente deposição no solo face o desprendimento dos bolos fecais estabelecidos sobre a superfície (PAISANI, 2015; PAISANI et al., 2016).

Os fitólitos passíveis de identificação morfológica são dominados por Elongate (22,38 a 24,90\%), seguido do Bulliform (14,29 a 5,72\%) já com sinais de alteração química. Em proporções que variam de $<1$ a $4 \%$ ocorrem Acicular, Bilobate, Rondel e Saddle (Figura 6). Os morfotipos Bilobate, Bulliform, Elongate, Rondel e Saddle são mencionados na literatura como indicadores taxonômicos (relação direta entre tipo de fitólito e táxon de planta) de gramíneas (Poaceae) (COE et al., 2014).

\subsection{Geocronologia dos registros estratigráficos}

A matéria orgânica datada do horizonte $25 \mathrm{Cg} 5 \mathrm{~b}$, localizado na sequência pedogenética hidromórfica (Figura 4B, 5A), apresentou cronologia de $27.980 \pm$ 2.650 anos AP (31.890 a 31.400 cal. anos AP - Tabela 2). Comparando essa idade com a estratigrafia do quaternário balizada pelos estágios isotópicos do oxigênio, pode-se dizer que esse paleossolo se estabeleceu durante o Último Interestadial. Embora seu horizonte superior A tenha sido removido pela erosão mecânica, essa idade é importante, pois mostra que o paleossolo hidromórfico esteve funcional, no fundo de vale de segunda ordem sob condições hídricas úmidas.

Os grãos de quartzo do horizonte $15 \mathrm{Cb}$, limite superior da sequência coluvial basal (Figura 4B, 5A), apresentaram idade média de $19.150 \pm 2.650$ anos AP pela luminescência oticamente estimulada - LOE (Tabela 2). Considerando a margem de erro, pode-se pensar que a sequência coluvial basal com níveis pedoestratigráficos $21 \mathrm{Cg} 1 \mathrm{~b}$ a $15 \mathrm{Cb}$ se estabeleceram entre 21.800 a 16.500 anos AP. Tal intervalo é compatível com o período paleoambiental conhecido como Último Máximo Glacial. 


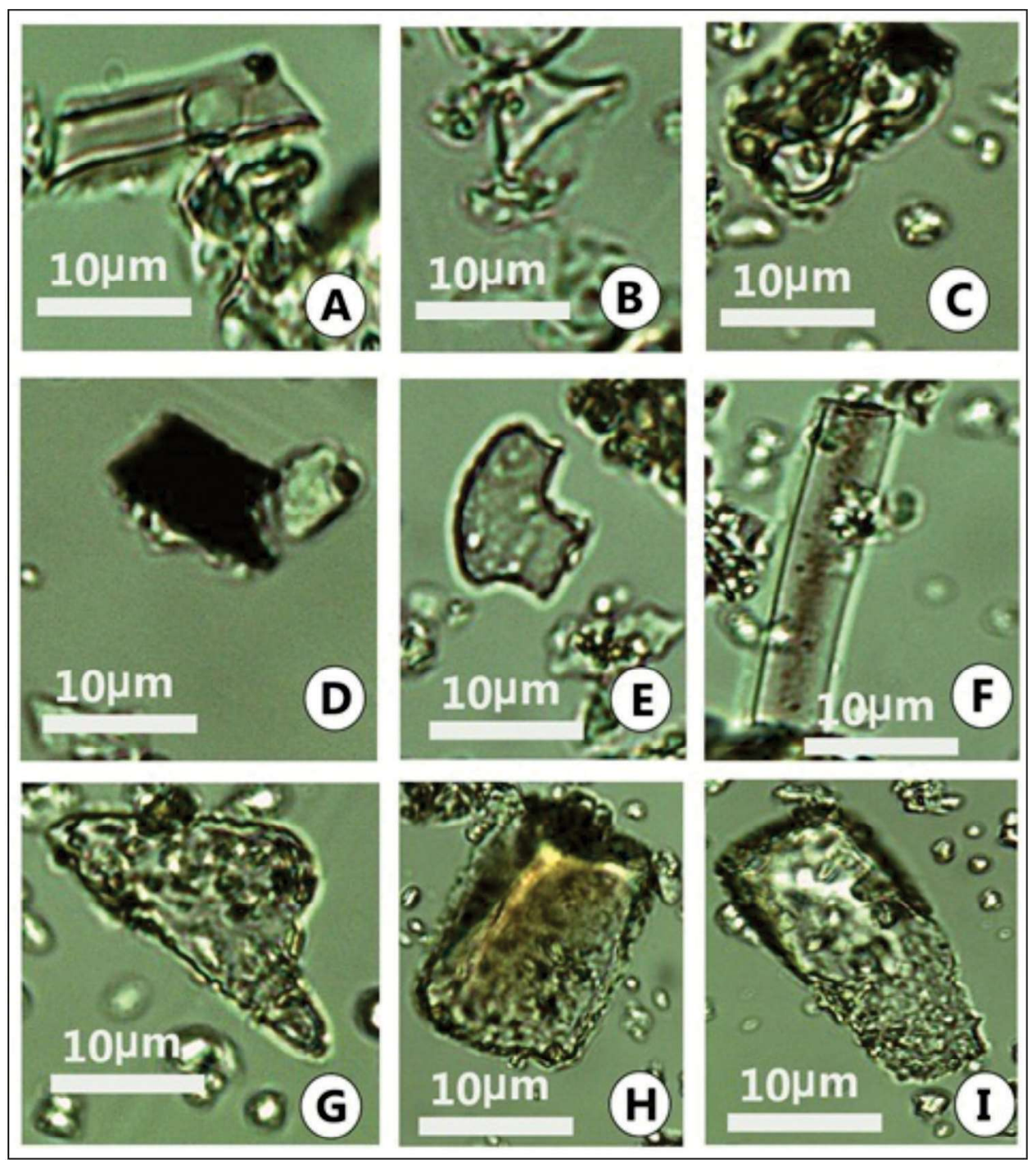

Figura 6 - Morfotipos de fitólitos Saddle (A), Rondel (B), Bilobate (C), Carbonizado (D), alterado fisicamente (E), Elongate (F), Acicular (G), Bulliform (H) e alterado quimicamente (I).

Já, os grãos de quartzo do horizonte $14 \mathrm{Cb}$, base da sequência intermediária, apresentaram idade média de $7.940 \pm 810$ anos AP obtida pela LOE (Tabela 2), o que corresponde ao início do Holoceno Médio. A idade dessa unidade foi fundamental para se compreender o quadro evolutivo do fundo de vale, pois demarca a cronologia da retomada da sedimentação - após período de ausência desse fenômeno e do desenvolvimento de incisão erosiva a partir de uma paleosuperfície. Tomando-se por base a idade do horizonte $15 \mathrm{Cb}$, percebe-se que entre $19.150 \pm$ 2.650 e $7.940 \pm 810$ anos AP(Tabela 2) houve estabilização na sedimentação, desenvolvimento de paleosuperfície e subsequente intensificação da erosão mecânica. Essa sequência de fatos geomórficos coincide com o final do Último Máximo Glacial e se estendeu até o Holoceno Inferior.

Já, a retomada da sedimentação, ocorreu a partir do Holoceno Médio em direção ao presente. Os grãos de quartzo do horizonte $3 \mathrm{Cb}$, topo da sequência coluvial intermediária, apresentaram idade média de $4.860 \pm 675$ anos AP (Tabela 2), sugerindo que tal sequência coluvial se desenvolveu plenamente durante o Holoceno Médio e que a sequência coluvial superior pedogenizada (horizontes $\mathrm{AC}, \mathrm{AC}$ e CA - Figura 4B, 5A) se estabeleceu durante o Holoceno Superior.

5. Evolução geomorfológica do paleofundo de vale de segunda ordem hierárquica e correlações regionais

Os resultados da arquitetura dos registros estratigráficos, juntamente com as análises laboratoriais realizadas, permitem apresentar um quadro evolutivo local do paleofundo de vale estudado. Igualmente, permitem reconstituir os momentos de pedogênese e 
morfogênese na área situada em São José Dos Ausentes (RS) e estabelecer correlação com eventos similares na superfície de Palmas/Caçador e eventos paleoclimáticos regionais e globais.

A arquitetura do registro estratigráfico revelou que o paleofundo de vale apresentava morfologia suavemente côncava em seu eixo central, similar aos eixos de fundos de vales modernos encontrados na área de estudo em que não ocorrem canais incisivos. Os eixos de drenagem modernos são dominados por solos hidromórficos e fluxos de água hipodérmicos, constituindo áreas de brejo similares àquelas encontradas na superfície de Palmas/Caçador (PAISANI et al., 2014). Tal aspecto é importante, pois mostra que durante dado período a rede de drenagem de baixa ordem setorial exibia baixa energia de transporte fluvial e que o ambiente de encosta estava em estado de equilíbrio dinâmico (PAISANI et al., 2012), favorecendo os processos de espessamentos dos solos tanto nas encostas quanto no fundo de vale - processo designado de pedogênese progressiva conforme Johnson et al. (1990).

Embora o período fosse favorável ao espessamento dos solos nas encostas e no entorno do fundo de vale analisado, a mineralogia dos materiais e a micromorfologia sugerem que se tratava de solos jovens e relativamente rasos, possivelmente da categoria dos Cambissolos (PEREIRA, 2017). A presença dominante de goethita permite inferir que o regime climático era relativamente úmido, com boa distribuição de chuvas, pequena evapotranspiração, baixas temperaturas, teores elevados de matéria orgânica, meio ácido e restrição de drenagem (PEREIRA, 2017). De fato, a composição isotópica do carbono dos níveis pedoestratigráficos remanescentes dessa fase (horizontes $26 \mathrm{Cg} 6 \mathrm{~b}$ a $15 \mathrm{Cb}$ ) sugere a presença de plantas $C_{3}$, padrão de fotossíntese comum em arbustos e árvores. Nessas condições, o fundo de vale em análise desenvolveu solo hidromórfico devido à contínua manutenção de umidade (Figura 7).

Tabela 2: Idades ${ }^{14} \mathrm{C}$ e Luminescência Oticamente Estimulada dos registros estratigráficos da Seção SJA1.

\begin{tabular}{|c|c|c|c|c|c|c|c|c|}
\hline \multicolumn{9}{|c|}{${ }^{14} \mathrm{C}$} \\
\hline Horizonte & $\begin{array}{l}\text { Prof. } \\
\text { (cm) }\end{array}$ & \multicolumn{2}{|c|}{ Cód.Lab. } & \multicolumn{2}{|c|}{ Idade $\left(\operatorname{anos}{ }^{14} \mathrm{C} \mathrm{AP}\right)$} & \multicolumn{2}{|c|}{$\begin{array}{c}\text { Idade (anos cal. }{ }^{14} \mathrm{C} \\
\text { AP) }\end{array}$} & $\delta^{13} \mathbf{C}(\%)$ \\
\hline $25 \mathrm{Cg} 5 \mathrm{~b}$ & & \multicolumn{2}{|c|}{420524} & \multicolumn{2}{|c|}{$27.980 \pm 130$} & \multicolumn{2}{|c|}{31.890 a 31.400} & -24.1 \\
\hline \multicolumn{9}{|c|}{ Luminescência Oticamente Estimulada (LOE) } \\
\hline Horizonte & $\begin{array}{l}\text { Prof. } \\
\text { (cm) }\end{array}$ & Cód.Lab. & Th (ppm) & $\mathbf{U}(\mathbf{p p m})$ & $\mathbf{K}(\%)$ & $\begin{array}{l}\text { Dose Anual } \\
\left(\mu G y \cdot \text { ano }^{-1}\right)\end{array}$ & P (Gy) & $\begin{array}{l}\text { Idade (anos } \\
\text { A.P.) }\end{array}$ \\
\hline $3 \mathrm{Cb}$ & 160 & 4524 & $19,758 \pm 0,711$ & $6,623 \pm 0,632$ & $1,079 \pm 0,156$ & $4.240 \pm 380$ & 20,6 & $4.860 \pm 675$ \\
\hline $14 \mathrm{Cb}$ & 380 & 4525 & $19,675 \pm 0,636$ & $6,049 \pm 0,217$ & $0,477 \pm 0,069$ & $3.390 \pm 175$ & 26,6 & $7.940 \pm 810$ \\
\hline $15 \mathrm{Cb}$ & 170 & 4571 & $12,095 \pm 0,435$ & $3,914 \pm 0,401$ & $0,749 \pm 0,109$ & $2.820 \pm 250$ & 54,0 & $19.150 \pm 2.650$ \\
\hline
\end{tabular}

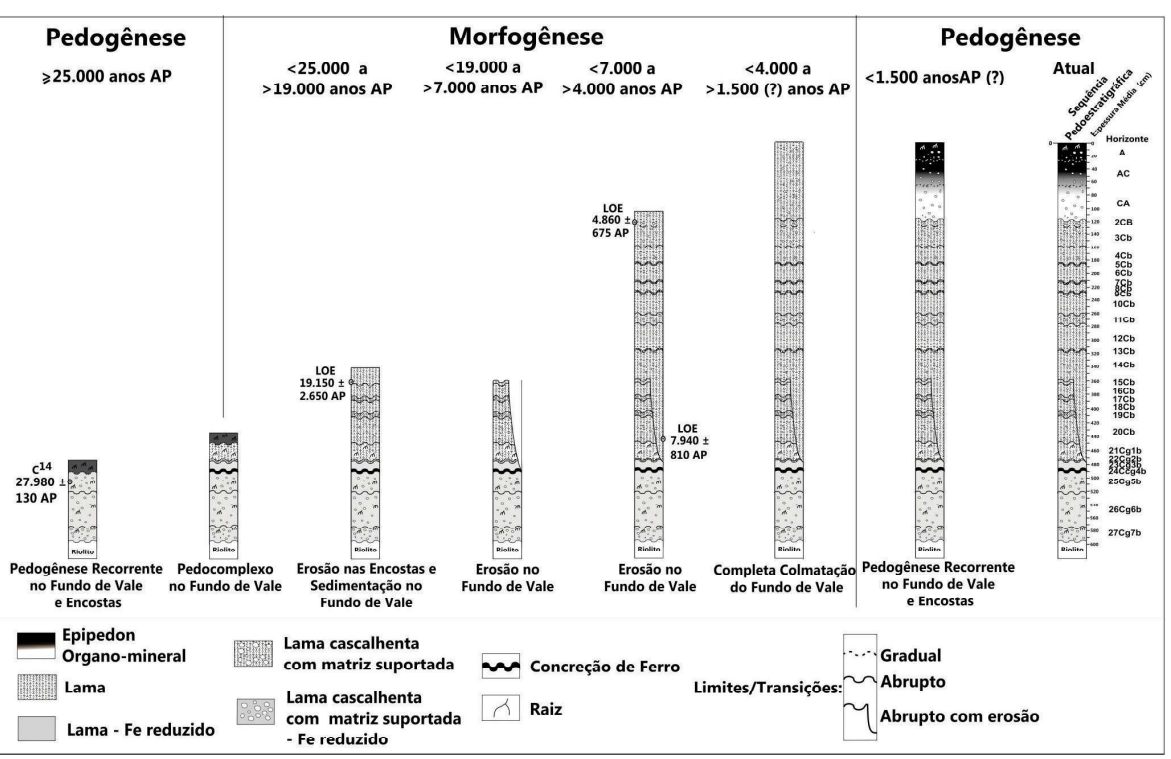

Figura 7 - Esboço da sequencia temporal de eventos de pedogênese e morfogênese no paleofundo de vale de segunda ordem. 
A manutenção das condições de umidade "fossilizaram" raízes no horizonte $25 \mathrm{Cg} 5 \mathrm{~b}$, e promoveram a quantidade de carbono suficiente para aplicação da datação pelo método do ${ }^{14} \mathrm{C}$. No registro estratigráfico há ausência de horizonte $\mathrm{A}$, truncado posteriormente pela erosão, cuja cronologia deveria ser mais jovem que aquela obtida para o horizonte $25 \mathrm{Cg} 5 \mathrm{~b}$, simplesmente por ter estado sobreposto a referido horizonte. De todo modo, na discussão dos resultados da geocronologia ficou claro que a condição de equilíbrio dinâmico no local analisado ocorreu em concordância com o período do Último Interestadial (entre 60.000 a 25.000 anos cal. AP) e apresenta correlação estratigráfica com os registros obtido nos paleofundos de vale de baixa ordem da superfície de Palmas/Caçador (PAISANI et al., 2014; 2016). A umidificação climática à época foi de cunho regional, como demonstrada nos referidos registros estratigráficos e por dados palinológicos (PAISANI et al., 2019). A umidificação climática à época foi de cunho regional, como apontam dados palinológicos (BEHLING et al., 2004).

Subsequente a esse período, houve desequilíbrio na paisagem, pedogênese regressiva na conceituação de Johnson et al. (1990), em que os processos de erosão mecânica nas encostas começaram a se sobressair e promover a colmatação do fundo de vale. Os níveis pedoestratigráficos $21 \mathrm{Cg} 1 \mathrm{~b}, 22 \mathrm{Cg} 2 \mathrm{~b}$ e $23 \mathrm{Cg} 3 \mathrm{~b}$ delgados e truncados posteriormente pela erosão, documentam que a ocorrência de movimento de massa discretos nas encostas levaram sedimentos para o fundo de vale ainda em condições ambientais relativamente úmidas (Figura 7). Esse fenômeno deve ter sido na transição entre o final do Último Interestadial e o Último Máximo Glacial, quando ainda persistiam a hidromorfia no fundo de vale, pois as descrições morfopedológicas em campo apontam condições redox no horizonte $21 \mathrm{Cgb}$. Por outro lado, o desenvolvimento de crosta de ferro (horizonte $24 \mathrm{Ccg} 4 \mathrm{~b}$ ) em sua base sugere situação de sazonalidade hídrica nesse período de transição (Figura 4B, 7). Na superficie de Palmas/Caçador esse fenômeno gerou registros pedoestratigráficos com até três níveis de horizontes $\mathrm{Ab}$ (pedocomplexo), situado acima de colúvios gerados por sedimentação episódica no transcurso na pedogênese antes de 24.000 anos AP (PAISANI et al., 2014).

No Último Máximo Glacial a morfogênese passou a ser comandada pelo escoamento superficial, gerando sedimentos em leitos delgados com diferentes intensidades de retrabalhamento, ora com o predomínio de matriz ora com predomínio de fração grossa (linha de pedras), como documentam a análise morfopedológica e micromorfológica realizada por Pereira (2017). Registros desses últimos retrabalhamentos são os níveis pedoestratigráficos caracterizados por linhas de pedras (horizontes $17 \mathrm{Cb}$ e $15 \mathrm{Cb}$ ) (Figura 4B, 5A, 6). Essa fase perdurou entre $>25.000 \mathrm{a}>19.150 \pm 2.650$ anos AP. (Figura 7). Em paleofundos de vales de baixa ordem da superfície de Palmas/Caçador foram registrados, de forma não sistemática, raros movimentos de massa discretos até cerca de 18.000 anos AP (GUERRA e PAISANI, 2012; PAISANI et al., 2016; LIMA, 2016).

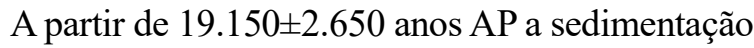
perdeu intensidade e passou a predominar a erosão, como documenta a incisão erosiva linear (paleovoçoroca) que truncou os níveis pedoestratigráficos $15 \mathrm{Cb}$ a $20 \mathrm{Cb}$ (Figura 7). Essa fase durou entre $<19.150 \pm 2.650$ a $>7.940 \pm 810$ anos AP e foi responsável pelo retrabalhamento do nível pedoestratigráfico $15 \mathrm{Cb}$. Correlacionando com os eventos paleoambientais globais, corresponde à transição do Último Máximo Glacial/Holoceno até o final do Holoceno Inferior. Os indícios da paleovegetação dessa fase ficaram registrados nos materiais da sequência pedoestratigráfica intermediária (horizontes $14 \mathrm{Cb}$ e $6 \mathrm{Cb}$ ), os quais guardam em seus materiais o sinal paleoambiental da área fonte dos sedimentos nessa fase. Percebe-se que havia a mistura de vegetação $\mathrm{C}_{3} \operatorname{com~}_{4}$, fenômeno indicativo de vegetação mais aberta decorrente de mudança do regime hídrico local para mais seco.

Na superfície de Palmas/Caçador o fenômeno de erosão linear também foi documentado em paleofundos de vales de $2^{\mathrm{a}}$ ordem, bem como no hollow de paleocabeceiras de drenagem (PAISANI et al., 2016; LIMA, 2016). Nessa superfície foram encontradas até três gerações de incisões lineares (paleovoçorocas), a primeira estabelecida no intervalo de $<24.460$ a $>16.750$ anos AP, a segunda entre $<16.750$ a $>6.800$ anos AP e a terceira no espaço de tempo de $<6.800$ a $>4.600$ anos AP (PAISANI et al., 2016). Considerando as margens de erro das idades obtidas para o registro estratigráfico dos materiais da seção em análise, pode-se pensar que o fenômeno de erosão linear é cronologicamente correlato à segunda geração de paleovoçoroca encontrada em paleocabeceira de drenagem da superfície de Palmas/Caçador.

Após essa fase de predomínio da erosão mecânica em detrimento da sedimentação, a morfogênese retorna a registrar sedimentação igualmente comandada pelo escoamento superficial, gerando sedimentos em leitos delgados com diferentes intensidades de retrabalhamento, ora com o predomínio de matriz, ora com predomínio de fração grossa (linha de pedras). A sequência coluvial 
intermediária foi gerada nessa fase (horizontes $14 \mathrm{Cb}$ a $2 \mathrm{Cb}$ ) e durou o intervalo de $<7.940 \pm 810$ a $>4.860 \pm 675$ anos AP (Figura 7), período equivalente ao Holoceno Médio. Com a contínua retirada do solo na área da fonte os corestones do front de intemperismo passaram a aflorar na superfície e a se desmantelar gerando os modernos caos de blocos de riolito.

A morfogênese continuou atuando após $4.860 \pm 675$ anos AP gerando a sequência coluvial superior que foi pedogenizada (melanizada) formando os horizontes $\mathrm{A}, \mathrm{AC}$ e CA. Pelos dados paleoambientais regionais, acredita-se que essa fase de pedogênese deve ter iniciado há cerca de 1.500 anos AP, quando se estabeleceu plenamente no âmbito regional a cobertura florestal destacada pela presença de Araucárias (BEHLING et al., 2004). Por outro lado, o sinal isotópico do carbono da sequência superior aponta paulatina substituição de plantas $\mathrm{C}_{3}$ por $\mathrm{C}_{4}$, com predomínio dessa última até as condições ambientais modernas.

\section{Conclusão}

Objetivando contribuir aos estudos de registros estratigráficos quaternários no Sul do Brasil, mais especificamente na Superfície Cimeira de Vacaria, RS o levantamento pedoestrafigráfico do paleofundo de vale de São José dos Ausentes, RS, permitiu compreender o seu quadro evolutivo. Igualmente, possibilitou reconhecer eventos similares na Superfície de Palmas/Caçador e eventos paleoclimáticos regionais e globais.

Em síntese os registros estratigráficos do paleofundo de vale mostraram que durante o Último Interestadial (>25.000 anos AP) havia solo hidromórfico e fluxos de água hipodérmicos em seu eixo de drenagem, configurando na paisagem como área de brejo similar àquelas encontradas na atualidade, tanto na área de estudo quanto na superfície de Palmas/Caçador. Em tal fase, a paisagem esteve em equilíbrio dinâmico, com dominante atuação da pedogênese, sob condições paleoambientais similares à moderna, embora predominasse vegetação de plantas $\mathrm{C}_{3}$ no tanto no fundo de vale quanto nas encostas.

Posterior a esse período houve a atuação da morfogênese atuando de maneira contínua, geradas pela intercalação entre dois processos envolvidos, movimentos de massa discretos e escoamento superficial. Os movimentos de massa discretos foram responsáveis pela sedimentação do fundo de vale ainda em condições ambientais úmidas, responsável pelo truncamento do material hidromórfico caracterizado como paleossolo enterrado, sendo que esse fenômeno deve ter sido na transição entre o final do Último Interestadial e o Último Máximo Glacial.

Durante o Último Máximo Glacial a morfogênese passou a ser comandada pelo escoamento superficial. Entre $>25.000$ a $>19.150$ anos AP a sedimentação de unidades coluviais estabeleceu os níveis pedoestratigráficos $23 \mathrm{Cg} 3 \mathrm{~b}$ a $15 \mathrm{Cb}$. A partir de $19.150 \pm 2.650$ anos AP a sedimentação perdeu intensidade e passou a predominar a erosão, como se observa através da incisão erosiva linear (paleovoçoroca) que truncou material coluvial da seção estratigráfica. Essa fase de erosão tem correlação cronológica com a segunda geração de incisões lineares documentadas na superfície de Palmas/Caçador, tendo durado entre $<19.150$ a $>7.940$ anos AP se estendendo até o final do Holoceno Inferior.

Seguidamente à fase de erosão mecânica a morfogênese retorna a registrar sedimentação comandada pelo escoamento superficial. Em decorrência, foram geradas unidades coluviais referentes aos níveis pedoestratigráficos $14 \mathrm{Cb}$ a $2 \mathrm{Cb}$. Tal fase durou entre $<7.940 \mathrm{a}>4.860$ anos AP equivalendo ao Holoceno Médio.

Após 4.860 anos AP a morfogênese continuou atuando, dando origem à sequência coluvial superior, porém perdeu vigor favorecendo a melanização no material, o que propiciou a formação dos horizontes A, AC e CA. Nessa fase o paleofundo de vale de segunda ordem hierárquica passou a ser plenamente colmatado e reafeiçoado, deixando na paisagem uma morfologia similar à encosta suavemente inclinada para o eixo de baixa ordem hierárquica moderno.

Contudo, diante do quadro evolutivo do paleofundo de vale entende-se que os fenômenos de pedogênese e morfogênese registrados expressam a dinâmica pela qual passou a paisagem geomorfológica de São José dos Ausentes (RS).

\section{Agradecimentos}

Ao CNPq pelo fomento a pesquisa (Proc. 441647/2014-6) e a CAPES pela bolsa de Mestrado.

\section{Referências Bibliográficas}

ALEXANDRE, A.; MEUNIER, J.D.; LÉZINE, A.M.; VINCENS, A.; SCWARTZ, D. Phytoliths: indicators of grassland dynamics during the late Holocene in intertropical Africa. Palaeogeography, Palaeoclimatology, Palaeoecology, Amsterdam, v. 136, p. 213-229. 1997. 
ALVAREZ, M.F., BORRELli, N., OSTERRIETH, M. Extracción de biominerales silícios en distintos sedimentos utilizando dos técnicas básicas. British Archaeological Reports (BAR), Oxford, p.31-38. 2008.

ARAÚJO, A. G. M.; PAISANI, J. C.; SCHRAGE, T. J.; FEATHERS, J. K.; HARTMANN, G. A.; RICCI, O.; The "Lagoa do Camargo 1" Paleoindian site: some implications for tropical geomorphology, pedology, and paleoenvironments in southeastern Brazil. Geoarchaeology - An International Journal. v. 00, p. 1-16, 2017.

BEHLING, H.; PILLAR, V.D.; ORLÓCI, L.; BAUERMANN, S.G. Late Quaternary Araucaria forest, grassland (Campos), fire and climate dynamics, studied by high-resolution pollen, charcoal and multivariate analysis of the Cambará do Sul core in southern Brazil. Palaeogeography, Palaeoclimatology, Palaeoecology, v. 204, p. 277-297, 2004.

BIFFI, V. H. R. PAISANI, J, C. Superfícies de Cimeira do Planalto Das Araucárias - Sul do Brasil. Revista Brasileira de Geomorfologia, São Paulo, v.19, n.3, p.465-481, 2018.

CALEGARI, M.R. Ocorrência e Significado Paleoambiental do Horizonte A Húmico em Latossolos. 2008. 256p. Tese de Doutorado, Escola Superior de Agricultura "Luiz de Queiroz"ESALQ/USP, 2008.

CALEGARI, M.R.; MADELLA, M.; VIDALTORRADO, P.; OTERO, X.L.; MACIAS, F.; OSTERRIETH, M. Opal phytolith extraction in oxisols. Quaternary International, v.287, p.5662,2013

CAVAZINI, A. J.; FUJITA, R. H.; PAISANI, J. C. Caracterização morfométrica da bacia hidrográfica do rio dos touros, São José dos Ausentes - RS. XI Simpósio Nacional de Geomorfologia, n. 514, 2016, Maringá (PR). Anais XI Simpósio Nacional de Geomorfologia, Maringá, 2016.

COE, H. H. G.; OSTERRIETH, M. L.; HONAINE, M. F. Phytoliths and their applications In: COE, H. H. G.; OSTERRIETH, M. L. (Org.) Synthesis of some phytolith studies in South America (Brazil and Argentina), Botanical Research and Practices. New York: Nova, 2014. p.1-26.

COSTA, L. M. et al. Ocorrência de corpos silicosos em horizontes superficiais de solos de diferentes ecossistemas. Revista Brasileira de Ciências do Solo. v, 34, p. 871-879, 2010.

GUEDES, C. C. F.; SAWAKUCHI, A. O.; GIANNINI, P. C. F.; DE WITT, R.; AGUIAR, V. A. P. Datação por luminescência opticamente estimulada: princípios e aplicabilidade nos depósitos sedimentares brasileiros. In: Congresso da Associação Brasileira de Estudos do Quaternário - ABEQUA, 13, 2011.
Anais... Búzios-RJ, 2011.

GUERRA, S.; PAISANI, J. C.; Levantamento estratigráfico das Formações Superficiais Cenozóicas no Planalto de Palmas (PR) e Água Doce (SC): subsídios ao estudo da evolução da paisagem a partir do Estágio Isotópico Marinho 3. Ambiência (UNICENTRO), v. 8, p. 651-665, 2012.

HOGG, A. G., HUA, Q., BLACKWELL, P. G., NIU, M., BUCK, C. E., GUILDERSON, T. P., HEATON, T. J., PALMER, J. G., REIMER, P. J., REIMER, R. W., TURNEY, C. S. M., \& ZIMMERMAN, S. R. H. (2013). SHCal13 Southern Hemisphere Calibration, 0-50,000 Years cal BP. Radiocarbon, 55(4).

HUGHES, P. D. Geomorphology and Quaternary stratigraphy: role of morpho-, litho-, and alloestratigraphy. Geomorphology, n. 123 , p. 189-199, 2010.

IBGE - EMBRAPA. Mapa de solos do Brasil. Rio de Janeiro: IBGE, 2001. Escala 1:5.000.000. 2001.

IBGE -. Mapa de Vegetação do Brasil. Rio de Janeiro: IBGE, 2004. Escala 1:5.000.000. 2004

JOHNSON, D.L.; KELLER, E.A.; ROCKWELL, T.K. Dynamic depogenesis: new views on some key soil concepts, and a model for interpreting Quaternary soils. Quaternary Research, v.33, p.306-319, 1990.

KUINCHTNER, A.; BURIOL, G.A. Clima do Estado do Rio Grande do Sul segundo a classificação climática de Köppen e Thornthwaite. Disciplinarum Scientia, v.2, p.171-182, 2001.

LIMA, S. de; História da pedogênese, morfogênese e colmatação de duas cabeceiras de drenagem da superficie de palmas/ Água doce durante o quaternário tardio. 2016. Dissertação (Mestrado em Geografia). Universidade Estadual do Oeste do Paraná, Francisco Beltrão. 2016.

MADELLA, M., ALEXANDRE, A., BALL, T. International code for phytolith nomenclature (ICPN 1.0). Annals of Botany, Oxford University Press (OUP), 96, 253-260, 2005.

MILANI, E.J. Comentários sobre a origem e evolução tectônica da Bacia do Paraná. In: MANTESSO-NETO, Virgínio (Org.) et al. Geologia do Continente Sul Americano. São Paulo: Beca, p. 356-369, 2004.

MMA - MINISTÉRIO DO MEIO AMBIENTE. Programa Nacional de Capacitação de Gestores Ambientais: Módulo específico licenciamento ambiental de estações de tratamento de esgoto e aterros sanitários. Brasília: MMA, 2009. ISBN: 978-85- 7738-128-9.

OSTERRIETH, M.L.; MADELLA, M.; ZURRO, D.; 
ALVAREZ, M.F. Taphonomical aspects of silica phytoliths in the loess sediments of the Argentinean Pampas. Quaternary International, v.193, p. 70-79, 2009.

PAISANI, J. C. Descontinuidades hidrológicas, escoamento superficial e desenvolvimento de incisões erosivas em áreas de cabeceira de drenagem: estudo de caso na Colônia QueroQuero, Palmeira(PR). 1998. 184p. Dissertação (Mestrado em Geografia) - Universidade Federal de Santa Catarina, Florianópolis (SC), 1998

PAISANI, J. C.; PONTELLI, M. E.; GEREMIA, F.; FORTES, J. A. E. Análise de lineamentos na bacia do rio Quatorze sudoeste do Paraná. Revista Varia Scientia, Unioeste, v.5, v.10, p.65-74, 2005.

PAISANI, J.C.; PONTELLI, M.E.; CALEGARI, M.R. Evolução de bacias de baixa ordem hierárquica nos 41.000 anos AP - Brasil Meridional. Mercator, Fortaleza, v. 11, n. 26, p. 131-148, 2012.

PAISANI, J.C., CALEGARI, M.R., PONTELli, M.E., PESSENDA, L.C.R., CÔRREA, A.C.B., PAISANI, S.D.L., RAITZ, E. O papel das mudanças climáticas do Quaternário Superior na dinâmica evolutiva de paleovale de segunda ordem (Sul do Brasil). Revista Brasileira de Geomorfologia, v. 14, p.103-116, 2013.

PAISANI, J.C.; PONTELLI, M.E.; OSTERRITH, M.L.; PAISANI, S.D.; FACHIN, A.; GUERRA, S.; OLIVEIRA, L. Paleosols in low-order streams and valley heads in the Araucaria Plateau - record of continental environmental conditions in southern Brazil at the end of MIS 3. Journal of South American Earth Sciences, 54, 57-70, 2014.

PAISANI, S. D. L. Significado paleoambiental de silicofitólitos em rampa de colúvio e paleocabeceira de drenagem na superfície de Palmas - Água Doce. 2015. 118p. Dissertação (Mestrado em Geografia) - Universidade Estadual do Oeste do Paraná, 2015.

PAISANI, J. C.; FACHIN, A.; PONTELLI, M.E.; OSTERRIETH, M.L.; PAISANI, S.D.L.; FUJITA, R.H. Evolução de paleocabeceira de drenagem do rio Chopinzinho (Sul do Basil) durante o Quaternário Superior. Revista Brasileira de Geomorfologia, v.17, n.1, p.43-59. 2016.

PAISANI, S. D. L; PAISANI, J. C.; OSTERRIETH, M. L.; PONTELLI, M. E. Significado paleoambiental de fitólitos em registro pedoestratigráfico de paleocabeceira de drenagem superfície de palmas - água doce (Sul do Brasil). São Paulo, UNESP, Geociências, v. 35, n. 3, p.426-442, 2016.

PAISANI, J. C.; PAISANI, S. D. L.; OSTERRIETH, M.L.; PONTELLI, M. E.; FUJITA, R.H.. Dinâmica de rampa de colúvio na superfície de Palmas/Água Doce durante o Quaternário Tardio - Bases para compreender a evolução das encostas no Planalto das Araucárias. Revista Brasileira de Geomorfologia, v. 18, p. 783-799, 2017.

PAISANI, J. C.; LOPES-PAISANI, S. D.; LIMA, S.; RIBEIRO, F. D. J.; PONTELLI, M. E.; FUJITA, R. H. Paleoenvironmental dynamics of low-order paleovalleys in the Late Quaternary Palmas/Caçador Summit Surface - Southern Brazil. Catena, v. 182, pg. 104171, 2019b, DOI: 10.1016/j.catena.2019.104171.

PELUSO JUNIOR, V.A. O relevo do território catarinense. Geosul, n.2, p.7-69, 1986.

PEREIRA, J.S. Pedogênese e morfogênese na superfície de São José dos Ausentes (RS) no Quaternário Tardio: evidências em paleofundo de vale na bacia hidrográfica do rio dos Touros. 2017. 135p. Dissertação (Mestrado em Geografia) - Universidade Estadual do Oeste do Paraná, 2017.

PEREIRA, J. S.; PAISANI, J. C.; FUGITA, R. H.; PONTELLI, M. E.; HENDGES, E. R. Caracterização preliminar das formações superficiais das superfícies de São José dos Ausentes (RS)/ São Joaquim (SC). In. XI SINAGEO - Simpósio Nacional de Geomorfologia, 2016, Maringá (PR). Anais do XI SINAGEO - Simpósio Nacional de Geomorfologia. Maringá (PR), n. $331,2016$.

PESSENDA L.C.R., ARAVENA R,. MELFI A.J., BOULET $\mathrm{R}$. The use of carbon isotopes (C-13, C-14) in soil to evaluate vegetation changes during the Holocene in central Brazil. Radiocarbon, 38 (2), p. 191-201. 1996.

PESSENDA, L.C.R.; GOUVEIA, S.E.M; RIBEIRO, A.S.; ARAVENA, R.; BOULET, R.; BENDASSOLI, J.A. Isótopos do Carbono e suas Aplicações em estudos paleoambientais. In: Souza, C.L.G.; Suguio K.; Oliveira, P.C.; Oliveira M.A.S. Quaternario do Brasil. Ribeirão Preto SP: Holos Editora, p. $75-93,2005$.

PILLAR, V.P.; MÜLLER, S.C.; CASTILHOS, Z.M.S.; JACQUES, A.V.A. (Eds.) Campos Sulinos - conservação e uso sustentável da biodiversidade. Brasília: MMA/SBF/ DCB, 2009.

SCHAETZL, R.J.; ANDERSON, S. Soils: Genesis and Geomorphology. Cambridge University Press, Cambridge, UK, 833p. 2005.

SCHERER, C; LORSCHEITTER, M. L. Vegetation dynamics in the southern Brazilian highlands during the last millennia and the role of bogs in Araucaria forest formation. Quaternary International, 325:3-12, 2014. 
SCHLICK, F. E. Alternativas de Manejo Para os Campos de Cima da Serra. 2004. Tese de Doutorado. Faculdade de Agronomia, Programa de Pós-graduação em Zootecnia. Universidade Federal do Rio Grande do Sul, Porto Alegre, 2004. SELBY, M. J. Hillslope sediment transport and deposition. InK. Pye (Ed.), Sediment transport and depositional processes (pp. 61-87). Oxford: Blackwell Scientific Publications, 1994. SUGUIO, K. Geologia do Quaternário e mudanças ambientais. São Paulo: Paulo’s Comunicações e. Artes Gráficas, 1999. 362p.
SUGUIO, K. Geologia Sedimentar. São Paulo: Editora Edgard Blucher ltda, 2003. 400p.

STUIVER, M., REIMER, P.J., REIMER, R.W., 2018. CALIB 7.1 [WWW program]. at. http://calib.org, Accessed date: 20 August 2018.

WILDNER, W; RAMGRAB, G. E; LOPES, L. da C; IGLESIAS C. M. da F. Mapa Geológico do Estado do Rio Grande do Sul. Porto Alegre: CPRM, 2006, Escala: 1:750.000. Programa Geologia do Brasil. Superintendência Regional de Porto Alegre. 